\title{
Aislamiento e identificación de patógenos de la estirpe silvestre del ajo (Allium sativum $L$.)
}

\author{
Isolation and identification of pathogens \\ of wild garlic (Allium sativum L.)
}

Karina Astorga-Quirós'

Claudia Zúñiga-Vega²

William Rivera-Méndez ${ }^{3}$

Astorga-Quirós, K; Zúñiga-Vega, C; RiveraMéndez, W. Aislamiento e identificación de

patógenos de la estirpe silvestre del ajo (Allium sativum L.). Tecnología en Marcha.Vol.

27, № I. Pág 77-84 


\section{Palabras clave}

Control biológico; Allium sativum; Pseudomonas marginalis; Penicillium sp.; Sclerotium cepivorum.

\section{Resumen}

El cultivo del ajo (Allium sativum L.) en Costa Rica se podría convertir en una alternativa rentable para la producción y diversificación de los agricultores de hortalizas. Sin embargo, el tipo de reproducción vegetativa que presenta facilita la transmisión y diseminación de enfermedades, lo que provoca un debilitamiento progresivo de los bulbos.

Actualmente, se buscan alternativas de manejo diferentes al control químico, para disminuir el impacto ecológico y ambiental de los patógenos que lo afectan. El control biológico es una de ellas, pero presenta dificultades para el aislamiento y la identificación certera de patógenos asociados a pudriciones que se dan en el suelo. Por lo anterior, el objetivo general de esta investigación consistió en aislar e identificar a nivel de especie cepas de Pseudomonas marginalis, Penicillium sp. y Sclerotium cepivorum a partir de material vegetativo de ajo en campo, para su utilización en futuros trabajos de control biológico de estas enfermedades.

La metodología seguida permitió aislar e identificar con un alto porcentaje de certeza a P. marginalis, así como obtener cultivos monospóricos de Penicillium sp. y cultivos puros de S. cepivorum. Las técnicas descritas constituyen la base para futuros trabajos relacionados con las fitopatologías en el cultivo del ajo.

\section{Key words}

Biologic control; Allium sativum; Pseudomonas marginalis; Penicillium sp.; Sclerotium cepivorum.

\section{Abstract}

The garlic field (Allium sativum L.) in Costa Rica could become a profitable alternative for the production and diversification of the vegetable farmers. However, the type of vegetative propagation that it presents facilitates the transmission and dissemination of diseases, which produces a progressive weakening of the bulbs.

Currently, different options from chemical control are being searched, in order to reduce the ecological and environmental impact of the pathogens to it. Biologic control is one of them, but it presents difficulties in the isolation and accurate identification of pathogens associated to the decay that occurs in the soil. Therefore, the general objective of this research was to isolate and identify, at a species level, strains of Pseudomas marginalist, Peniciliium sp. and Sclerotium cepivorum, from vegetative material of garlic in field, for its utilization in future studies of biologic control of these diseases.

The followed methodology allowed us to isolate and identify P. marginalis with a high accurate percentage. Also, it allowed us to obtained single-spore cultures of Penicillium sp. and pure cultures of S.cepivorum. The described techniques constituted the basis for future works related to the plant diseases in the garlic production. 


\section{Introducción}

El ajo (Allium sativum L.) pertenece a la familia de las amarillidáceas (Amarillidaceae), subfamilia alioideas (Allioideae) (The Angiosperm Phylogeny Group, 2009). Es una especie ampliamente cultivada que ocupa el segundo lugar en importancia dentro del género Allium después de la cebolla (Ledezma y Apitz, 2006, FAO, 2012, Navarro, 2007, APG, 2009). Esta hortaliza se destaca porque posee fitoquímicos, fructanos (inulina) y compuestos organoazufrados como la alicina, que son importantes por sus propiedades antioxidantes, hipocolesterolémicas, antibacterianas, antifúngicas, antivirales y antiparasitarias; sin dejar de lado el uso culinario como condimento y conservante (Portela, 2007, Robinson, 2007).

En el campo, la producción se dificulta pues el ajo no produce semillas viables, por lo que se siembran los bulbos cosechados de la temporada anterior. Estas condiciones de reproducción vegetativa facilitan la transmisión y diseminación de las enfermedades, lo que causa un debilitamiento progresivo e irreversible de las variedades (García y Sánchez, 2000, Burba, 2009).

En Costa Rica, la dinámica de producción del ajo ha pasado de ser meramente familiar a un cultivo a pequeña escala, lo cual, unido a su alta estabilidad en el tiempo una vez seco, hace del cultivo una alternativa rentable para la producción.

El ajo es propenso al ataque de patógenos que causan enfermedades tanto en el follaje como en los bulbos, lo que limita los rendimientos y la calidad. Entre ellos se destacan Penicillium spp., que causa el llamado "moho verde"; Pseudomonas marginalis, promotor de la "podredumbre blanda", y Sclerotium cepivorum, asociado con la "podredumbre blanca" en raíces y bulbos (Rojas et al., 2009).

Las alternativas de manejo diferentes al control químico, como lo es el control biológico, representan una de las herramientas más viables desde el punto de vista ambiental y económico. Este control puede incluir el uso de bacterias, hongos, virus, plantas superiores y microfauna. Los agentes más estudiados en el caso del ajo son los géneros Streptomyces, Pseudomonas, Agrobacterium, Trichoderma y Bacillus (Reinoso et al., 2006, Izzeddin \& Medina, 20 I I). Uno de los principales problemas que se presenta con esta metodología es la dificultad que representa el aislar e identificar con certeza los patógenos asociados a pudriciones o descomposiciones que se dan en el suelo.

\section{Podredumbre verde o Moho azul (Penicillium spp.)}

El género Penicillium (Familia Moniliaceae, División Deuteromicotina, Orden Moniliales) es un hongo de crecimiento relativamente rápido, que inicialmente forma colonias blancas aterciopeladas, las cuales van adquiriendo diferentes colores según la especie; al final quedan cubiertas de esporas con un aspecto polvoriento. La colonia está constituida por micelio de hifas delgadas septadas (Arias y Piñeros, 2008).

Este microrganismo está presente en todos los ambientes y en el caso del ajo penetra en los bulbos, aprovechando heridas o cualquier condición de estrés durante la brotación y el crecimiento. Causa lesiones amarillas cubiertas por moho blanco que posteriormente cambia a azulado (por fructificaciones), lo que impide que el bulbillo brote y que, si lo logra, se muestre con poco vigor hasta la muerte. Su control se realiza desinfectando la semilla antes de la siembra (figura I) (Portela, 2007).

\section{Podredumbre blanca o Torbó (Sclerotium cepivorum Berkeley)}

Sclerotium cepivorum (Familia Sclerotiniaceae, División Eumycota, Orden Myceliales) afecta solamente a las especies de Allium y desarrolla estructuras de resistencia con una viabilidad mayor de $90 \%$. Puede formar esclerocios secundarios, dentro o adyacentes a los esclerocios originales, que influyen fuertemente en su supervivencia y tienen la capacidad de resistir en el suelo por más de 20 años sin perder su efectividad (Granados y Wang, 2008, Granados, 2005, Rivera, 20l I).

Su crecimiento se incrementa a altas temperaturas, de $20-27^{\circ} \mathrm{C}$, cuando invade las raíces y bulbos en
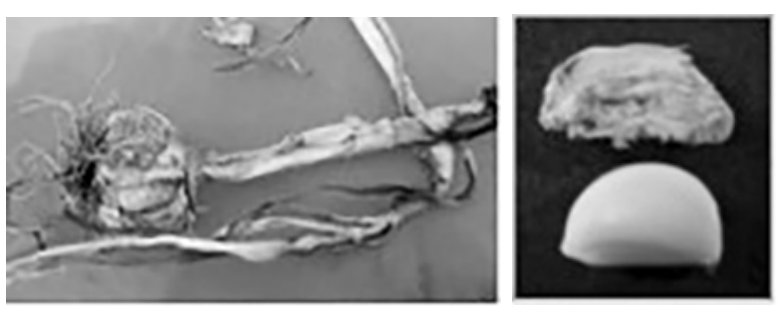

Figura I. Ataque de ajo por Penicillium. 
forma de un moho blanco y sedoso; posteriormente forma los esclerocios (lo cual es favorecido por temperaturas de $14-18^{\circ} \mathrm{C}$ ) (figura 2). La germinación de estas estructuras de resistencia es estimulada por compuestos de azufre presentes en los exudados radicales del cultivo, lo que provoca que si la planta es joven, se pudra y si el ataque es tardío, puede pasar desapercibido y desarrollarse durante el almacenamiento (Piccolo, 2007).

\section{Podredumbre blanda o bacteriosis (Pseudomonas marginalis o Erwinia rhapontici Burkholder)}

Pseudomonas marginalis o Enwinia rhapontici (Familia: Pseudomonadaceae, Orden Pseudomonadales) causa pudrición blanda de tubérculos, bulbos y tallos. En hojas, las lesiones iniciales en los márgenes evolucionan a lesiones oscuras de mayor tamaño. En condiciones de alta humedad y temperatura, el daño se puede extender a toda la planta (figura 3). En general se considera una bacteria oportunista que se trasmite a través de la lluvia, el viento y las prácticas culturales (Acuña, 2008).

\section{Control biológico}

En el suelo existe un equilibrio microbiológico que favorece la regulación natural de las poblaciones. La diversa cantidad de microorganismos que se encuentran en una fracción del suelo cumple fun-

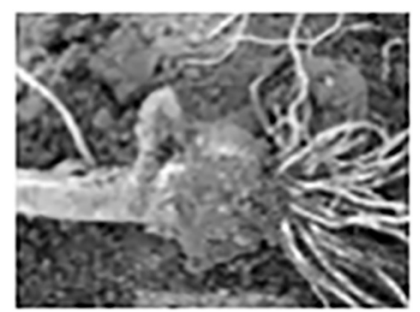

Figura 2. Ataque por Sclerotium cepivorum en ajo.

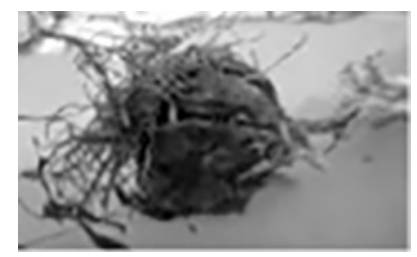

Figura 3. Ataque de ajo por Pseudomonas en campo. ciones determinantes en la transformación de los componentes orgánicos e inorgánicos. La utilización de microorganismos saprófitos pertenecientes a la flora edáfica para controlar patógenos vegetales representa una importante herramienta del control biológico. En los últimos años, la utilización de estos microorganismos antagonistas ha demostrado ser una alternativa frente al control tradicional con productos químicos. Sin embargo, en todas estas pruebas es fundamental disponer de aislamientos bien identificados y caracterizados del patógeno.

Es por ello que el objetivo general de esta investigación consistió en aislar e Identificar a nivel de especie cepas de Pseudomonas marginalis, Penicillium sp. y Sclerotium cepivorum a partir de material vegetativo de ajo (Allium sativum), para su utilización en futuros trabajos de control biológico de las plagas en campo.

\section{Materiales y métodos}

\section{Localización y material experimental}

Las pruebas y procedimientos se llevaron a cabo durante el segundo semestre de 2012 en las instalaciones del Centro de Investigación en Biotecnología (CIB) y en los laboratorios de la Escuela de Biología del Instituto Tecnológico de Costa Rica.

Para los bioensayos se emplearon muestras de tejido vegetal (bulbos de ajo), rizósfera y suelo con signos de las diferentes patologías en campo, procedentes de la zona norte de Cartago.

\section{Aislamiento y caracterización de Pseudomonas marginalis}

Se seleccionó material vegetativo de ajo (A. sativum) que presentaba signos de pudrición por Pseudomonas sp. Se lavaron los bulbos con agua potable y jabón y se desgranaron y colocaron en gasa estéril. A continuación se transfirieron a una cámara de flujo laminar y se sumergieron en alcohol al $70 \%$ por 30 s, en hipoclorito de sodio al $2 \%$ durante 10 s y $3 \mathrm{~min}$ en agua destilada estéril. Seguidamente se colocaron en placa Petri con filtro estéril por 2 min y con bisturí previamente esterilizado se cortaron en trozos con $50 \%$ de tejido sano y $50 \%$ enfermo. Se inocularon tres segmentos por placa en Agar B. de King a $28 \pm$ $2^{\circ} \mathrm{C}$ durante $24-48$ horas. Las colonias presuntivas se transfirieron a Agar B. de King y en Agar YDC, como medio confirmativo; posteriormente, las que 
se tornaron color crema se sembraron en medio $B$ de King nuevamente, de éstas se escogieron las que presentaron fluorescencia y se les aplicó la prueba Hugh \& Leifson para determinar movilidad y oxidación-fermentación.

Para la identificación de P. marginalis mediante Test API 20 NE se tomaron de I-3 colonias de cepas cultivadas en Agar B. de King y se suspendieron en solución salina ajustando la concentración a 0,5 escala Mc Farland, posteriormente se agregaron $200 \mu \mathrm{l}$ en medio James (2000) y se colocaron las alícuotas en las cúpulas. La lectura de los resultados se realizó a las 24 y 48 horas.

\section{Aislamiento y caracterización de Penicillium spp.}

Se seleccionaron bulbos con signos de moho azul en campo, posteriormente fueron colocados en cámaras de germinación sobre una bandeja de aluminio con papel filtro húmedo durante un periodo de 4 a 5 días, hasta el crecimiento del hongo. Los hongos fueron recuperados y transferidos a placas Petri con medio de cultivo PDA (agar-papa dextrosa, a razón de $2 \mathrm{ml}$ de ácido láctico al $10 \%$ por $100 \mathrm{ml}$ de medio) y se incubaron a $28-30^{\circ} \mathrm{C}$ por 72 horas. Seguidamente se realizó la caracterización e identificación a partir de la observación del crecimiento, color y aspecto de las colonias; por último, se identificaron a través de las claves taxonómicas para hongos imperfectos de Barnett \& Hunter (1998) y López y colaboradores (1998).

La obtención del cultivo monospórico de Penicillium se realizó a partir del inóculo del hongo aislado por 5 días y una vez esporulado se tomó una porción de tejido fúngico y se transfirió a un tubo Eppendorf ( ) de $1,5 \mathrm{ml}$ que contenía I ml de Tween 0,1\%, posteriormente se agitó en vórtex 15 s y se colocó en baño María 3 min. Se realizaron diluciones seriadas (hasta obtener de 50 a 100 esporas por $\mathrm{ml}$ en Cámara Neubauer), que se sembraron en $100 \mu \mathrm{l}$ de la dilución $10^{5}$ en medio PDA distribuida con espátula Drigalskiß. Se incubaron por 2 semanas, cuando se observó la germinación de una espora en microscopio a 400 aumentos, luego se transfirió a otra placa con PDA y se continuó con la incubación hasta el desarrollo total de la colonia (Arias y Pineros, 2008).

\section{Aislamiento de Sclerotium cepivorum}

Para el aislamiento primario de cepas de S. cepivorum se siguió la metodología descrita por Vimard y colaboradores (1986), que consiste en separar los esclerocios de las partículas del suelo mediante un gradiente de sacarosa y posteriores filtraciones. Cuando las cepas provenían de la colección micológica del $\mathrm{CIB}$, los esclerocios se desinfectaron, se colocaron en gasa y se transfirieron a cámara de flujo laminar; después se sumergieron en alcohol al 70\% por 30s, en hipoclorito de sodio producto comercial al 3\% 10 s y 3 min en agua destilada. Seguidamente se inocularon en medio Agar extracto de ajo (EAA) y PDA ac a $28^{\circ} \mathrm{C}$ por 5 días (Rivera, 201 I).

Además se desarrolló la técnica de cinta pegante para los género fúngicos (Penicillium, Sclerotium) que consistió en cortar $4 \mathrm{~cm}$ de cinta, que se tomó con pinzas y se presionó firmemente sobre la colonia del hongo, posteriormente esta tira se colocó en un portaobjetos con una gota de azul de lactofenol.

Las cepas de los hongos obtenidas a partir de su cultivo se identificaron con la clave taxonómica Barnett \& Hunter (1998) a partir de tinción con azul de lactofenol, para la diferenciación de estructuras.

\section{Conservación de cepas}

Los microorganismos aislados e identificados se conservaron en tubos inclinados con medio de cultivo y sellados con aceite estéril. Posteriormente se refrigeraron a $4^{\circ} \mathrm{C}$

\section{Resultados y discusión}

\section{Aislamiento e identificación de Pseudomonas marginalis}

El cultivo de las bacterias a partir de los bulbos de ajo condujo al aislamiento y la identificación de Pseudomonas (figuras 4 y $5 \mathrm{a}$ ). El crecimiento en el medio selectivo YDC facilitó el cultivo de microorganismos pertenecientes al género de interés, mientras que los medios Agar Eosina y Azul de metileno y agar glucosado terminaron de confirmar la identificación de colonias, que por su forma y cambio de coloración indicaban que se trataba de Pseudomonas.

Lo anterior se confirmó con las pruebas bioquímicas individuales mostradas en el cuadro I. Para la 

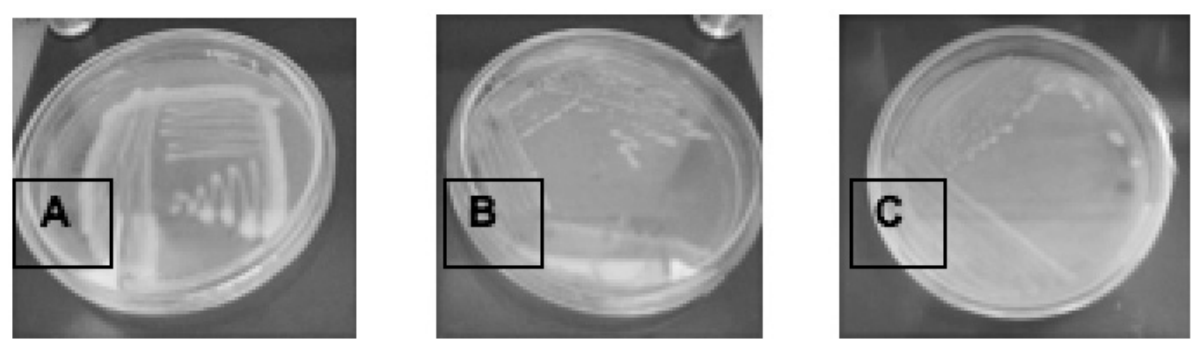

Figura 4. Aislamiento de Pseudomonas: a) crecimiento en medio selectivo YDC, b) cepa aislada en medio Agar Eosina y Azul de metileno, c) crecimiento en Agar Glucosado.
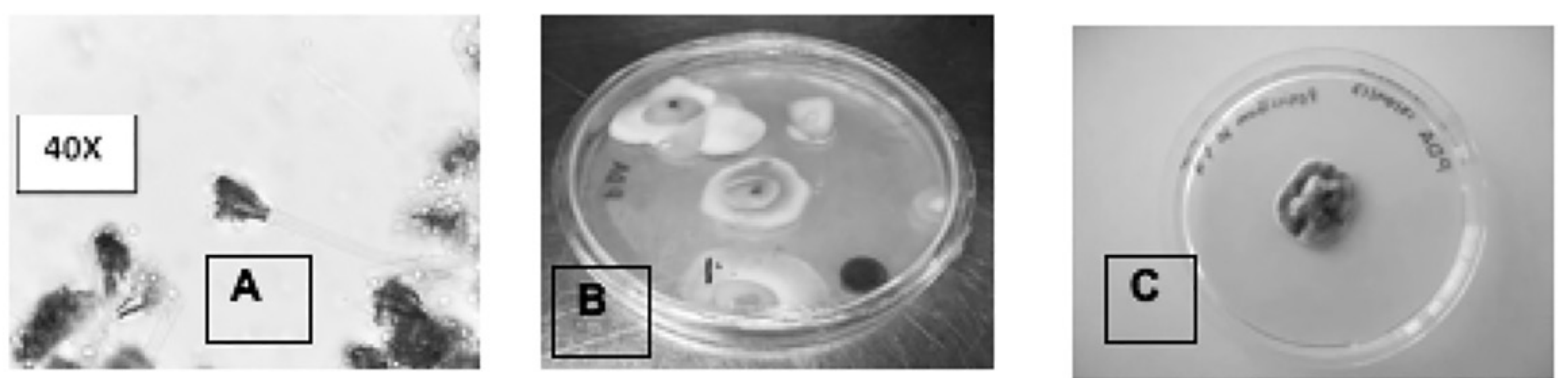

Figura 5. Aislamiento de Penicillium sp. En a. Conidios e hifas aumento 40X .b) En PDA a los 6 días de incubación $28 \pm 1{ }^{\circ} \mathrm{C}$. c.) Subcultivo monospórico en PDA ac.

caracterización a nivel de especie, la prueba API 20NE condujo a un 92,5\% de identificación para Pseudomonas marginalis (cuadro 2). Es importante recordar que el sistema de API se basa en reacciones miniaturizadas que brindan un código numérico, las cuales, con la utilización de un algoritmo específico determinan una serie de porcentajes de identificación. El porcentaje más alto representa una mayor probabilidad de identificación correcta.

Se considera que un $92,5 \%$ es un buen porcentaje de identificación, que está asociado a una alta probabilidad de que la bacteria sea P. marginalis.

\section{Aislamiento y caracterización de Penicillium spp.}

En lo que se refiere a los hongos, la cepa de Penicillium obtenida fue identificada con la clave taxonómica Barnett \&Hunter (1998) a partir de tinción con azul de lactofenol para la diferenciación de estructuras (figura 5a).

A este aislamiento se le realizó un proceso de cultivo monospórico, el cual garantiza la uniformidad del material genético (Figura 5b,c). Este procedimiento se considera fundamental si luego se quieren desa- rrollar estudios tendientes a la identificación de la especie.

\section{Aislamiento y caracterización de Sclerotium cepivorum}

Después de 5 días de incubación a $28^{\circ} \mathrm{C}$, a partir de los esclerocios cultivados se obtuvieron colonias bien desarrolladas. Estas presentan abundante micelio blanquecino y la formación de nuevos esclerocios en el borde la placa. La observación al microscopio a 400 y 1000 aumentos indicó que se trataba de la especie cepivorum por las estructuras tipo "clamp" y las características de las hifas (figuras 6 y 7 ).

\section{Conclusiones}

La metodología descrita permitió aislar e identificar positivamente colonias de Pseudomonas marginalis a partir de bulbos de ajo.

En lo que respecta a los hongos, se obtuvieron e identificaron con microscopía óptica cultivos monospóricos de Penicillium sp. y cultivos puros de Sclerotium cepivorum. 
Cuadro I. Resultados de pruebas de identificación para Pseudomonas.

\begin{tabular}{|c|c|}
\hline Pruebas & Pseudomonas \\
\hline Gram & Bacilos (-) \\
\hline B. de King & Positivo \\
\hline YDC & Colonias crema \\
\hline Prueba Hugh \& Leisson (O/F) & Oxidativo \\
\hline Sangre & Positivo \\
\hline Glucosado & Positivo \\
\hline Peptona & Positivo \\
\hline Motilidad & Positivo \\
\hline Catalasa & Positivo \\
\hline Nitrato & Positivo \\
\hline Agar Nutritivo I\% dextrosa & Negativo \\
\hline Voges Proskauer & Negativo \\
\hline Citrato Simmonds & Negativo \\
\hline Voges Proskauer & Negativo \\
\hline Tolerancia 6,5\% NaCl & Negativo \\
\hline Hidrólisis Almidón & Negativo \\
\hline Rojo de metilo & Negativo \\
\hline
\end{tabular}

Cuadro 2. Resultados de pruebas API de identificación para Pseudomonas.

\begin{tabular}{|c|c|}
\hline Pruebas & Pseudomonas \\
\hline L-triptofano & Api 20 NE Negativo \\
\hline D-Glucosa & Api 20 NE Positivo \\
\hline L-Arginina & Api 20 NE Negativo \\
\hline Urea & Api 20 NE Negativo \\
\hline Citrato Férrico & Api 20 NE Positivo \\
\hline Gelatina & Api 20 NE Positivo \\
\hline PNPG & Api 20 NE Positivo \\
\hline D-manosa & Api 20 NE Positivo \\
\hline D-manitol & Api 20 NE Positivo \\
\hline N-acetil Glucosamina & Api 20 NE Positivo \\
\hline D-maltosa & Api 20 NE Positivo \\
\hline Gluconato & Api 20 NE Positivo \\
\hline Ácido cáprico & Api 20 NE Negativo \\
\hline Ácido adípico & Api 20 NE Negativo \\
\hline Ácido málico & Api 20 NE Positivo \\
\hline Citrato trisódico & Api 20 NE Positivo \\
\hline Ácido fenilacético & Api 20 NE Negativo \\
\hline Citocromo oxidasa & Api 20 NE Negativo \\
\hline
\end{tabular}

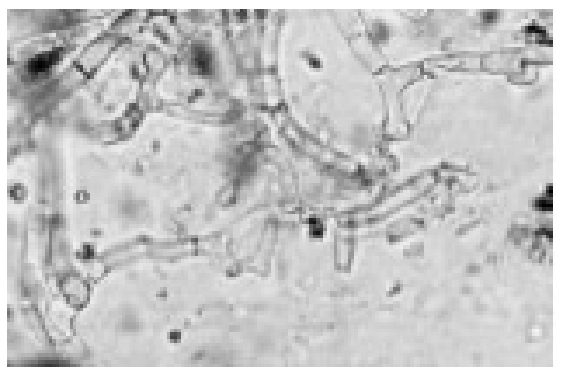

Figura 6. Vista al microscopio de Sclerotium cepivorum (400x).
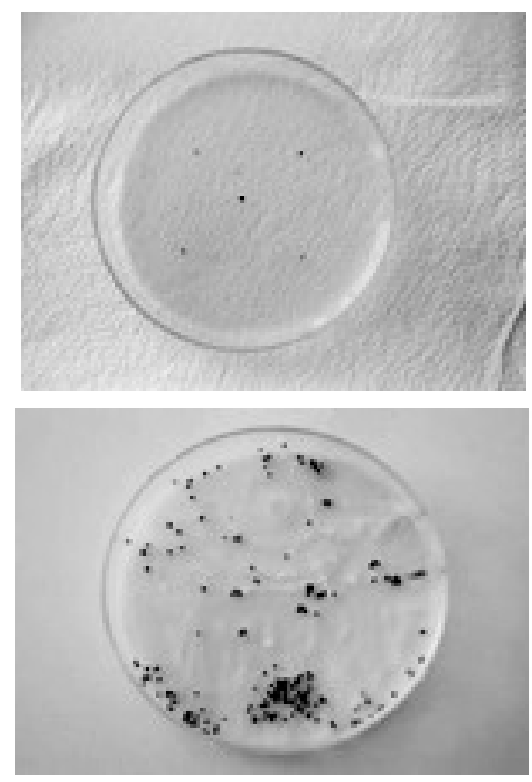

Figura 7. Cultivo de Sclerotium cepivorum: a) cultivo de esclerocios producidos in vitro, b) cultivo mediante discos con micelio.

Las técnicas descritas constituyen la base para futuros trabajos relacionados con las fitopatologías en el cultivo del ajo.

\section{Bibliografía}

Acuña, R. (2008). Compendio de Fitopatógenos de cultivos agrícolas en Chile. Departamento de Protección Agrícola. 122 pp.

APG. (2009). The Angiosperm Phylogeny Group 2009. An update of the Angiosperm Phylogeny Group classification for the orders and families of flowering plants: APG III. Botanical Journal of the Linnean Society |61, I05-121.

Arias, E. \& Piñeros, P. (2008). Aislamiento e identificación de hongos filamentosos de muestras de suelo de los Páramos de Guasca y Cruz Verde. Tesis Microbiología, Universidad 
Pontificia Javeriana, Bogotá, D.C. Consultado el 20 de septiembre de 2012. Disponible en: http://www.javeriana.edu. co/biblos/tesis/ciencias/tesis226.pdf.

Barnett, H.L. \& Hunter, B. (1998). Illustrated genera of imperfect fungi. 4 ed. Minnesota. US: Burgess Publishing Company, APS Press. p. 24l.

Burba, J.L. (2009). Garlic (Allium sativum L.) genetic improvement and seed production. Possibilities of adaptation to variable environments. Revista Colombiana de Ciencias Hortícolas 3 ( ) : 28-44.

FAO. (20I2). Base de datos estadística FAOSTAT. Consultado el 31 de agosto de 20 I2. Disponible en: http://faostat3.fao.org/ home/index_es.html?locale=es\#DOWNLOAD.

García, L.J. \& Sánchez, F.J. (2000). Revisión: Efectos cardiovasculares del ajo (Allium sativum). ALAN 50(3). Consultado el I 5 de septiembre de 2012. Disponible en: http://www.scielo.org. ve/scielo.php?.pid=S0004-06222000000300002\&script=sci_ arttext\&tlng=pt.

Granados, M. (2005). Pudrición blanca de la cebolla: una enfermedad difícil de combatir. Agronomía costarricense 29(2). Consultado el 15 de setiembre de 2012. Disponible en http://es.scribd.com/doc/767/3474/sclerotium-sp.

Granados, M.M. \& Wang, A. (2008). Efecto de biocontroladores aislados en fincas productoras de cebolla sobre la pudrición blanca (Sclerotium cepivorum). Revista Agronomía Costarricense 32 ( I):9-17. Consultado del 15 de septiembre de 2012. Disponible en: http://www.latindex.ucr.ac.cr/agrocostar-32-I/agrocostar-32-I-0 I.pdf.

Hugh, R. \& Leifson, E. (1953). The taxonomic significance of fermentative versus oxidative metabolism of carbohydrates by various gram-negative rods. J. Bacteriol. 66:2426. Consultado el 28 de octubre de 2012. Disponible en: (http://www.microbelibrary.org/component/resource/ laboratory-test/3 | 5 | -oxidative-fermentative-test-protocol).

Izzeddin, N. \& Medina, L. (20ll). Efecto del control biológico por antagonistas sobre fitopatógenos en vegetales de consumo humano. Salus 15(3). Consultado el 28 de octubre de 2012. Disponible en: http://www2.scielo.org.ve/scielo.php?script=sci_arttext\&pid=S | 3 | 67| 3820 | | $000300005 \&$ lng=es\&nrm=iso.

James, E. (2000. Nitrogen fixation in endophytic and associative symbiosis. Field Crops Research 65: 197-209.

Ledezma, E. \& Apitz, R. (2006). Ajoene, el principal compuesto activo derivado de ajo (Allium sativum), un nuevo agente antifúngico. Revista Iberoamericana de Micología 23: 75-80.
Consultado el 15 de septiembre de 2012. Disponible en: http://www.reviberoammicol.com/2006-23/075080.pdf.

López, M.O., Sandoval, I. \& Mena, J. ( 1998). Manual para la identificación de hongos fitopatógenos de la caña de azúcar en Cuba. Acta Botánica Cubana.

Navarro, M.C. (2007). Posibilidades terapéuticas del bulbo del ajo (Allium sativum). Revista de Fitoterapia 7(2):|31-|5|. Consultado en II de septiembre de 2012. Disponible en: http://www.fitoterapia.net/revista/pdf/RDF7-2\%20all.pdf

Piccolo, R. (2007). Enfermedades micológicas y bacterianas del Ajo (Allium sativum). Posgrado en Horticultura. INTA.

Portela, J.A. (2007). Ajo argentino: pautas de cultivo para la región Andina Central Argentina. La Consulta INTA EEA. $88 \mathrm{pp}$.

Reinoso, Y., Casadesús, L., García A., Gutiérrez J., Álvarez V. \& Álvarez, V. (2006). Aislamiento, selección e identificación de bacterias del género Bacillus antagonistas de Pectobacterium carotovorum. Fitosanidad 10: 187-191. Consultado el 28 de julio de 2012. Disponible en: http://redalyc.uaemex.mx/ redalyc/pdf/209|/209 | | 6 |0800 |.pdf.

Rivera, W. (201 I). Aislamiento y uso de cepas de Trichoderma spp. para el control biológico del hongo Sclerotium cepivorum Berkeley, causante de la pudrición blanda de bulbos de ajo (Allium sativum), con miras a la transferencia tecnológica a productores de la zona de Llano Grande de Cartago. Tesis Magister en Gestión de recursos naturales y Tecnologías de producción, Instituto Tecnológico de costa Rica. Consultado el 10 de octubre de 2012.

Robinson, R. (2007). Self-organising Agro-ecosystems. 2 ed. Sharebooks Publishing. Consultado el 30 de agosto 2012. Disponible en: http://ecoport.org/storedReference/559735. pdf.

Rojas, V., Ulacio, D.E., Sanabria, M.E. \& Jiménez, M.A. (2009). Efecto del calcio, Trichoderma y brócoli en la pared y área celular del ajo para el control de la pudrición blanca. Boletín. del Centro de Investigaciones Biológicas 43 (2). Consultado el 10 de septiembre de 2012. Disponible en: http://revistas.luz. edu.ve/index.php/bcib/article/view/340 I

Vimard, B., Leggett, M.E. \& Rahe, J.E. (1986). Rapid Isolation of Sclerotia of Sclerotium cepivorum from Muck Soil by Sucrose Centrifugation. Phytopathology 76: 465-467. 